\title{
Dissatisfied and Critical Citizens: the Political Effect of Complaining
}

\author{
Maciej Kowalewski ${ }^{1}$
}

Published online: 22 August 2019

(C) The Author(s) 2019

\begin{abstract}
Although complaining is well-recognized by psychologists and economists, its political potential is still far from obvious. Dissatisfaction with social services, non-democratic relationships between authorities and citizens, and the ignoring of significant social identities are communicated in everyday conversations. Even when complaining is perceived as 'grumbling', the informal nature of the communicated inconveniences may be more important than the formal participatory instruments through which collective claims are placed. Criticism and communication of grievances can lead to political activism only in particular circumstances. This article provides a conceptual frame of complaining enhancing into political claims. The proposed frame distinguishes between inactive complaining and complaining aimed at making a change, which may be reinforced or reduced. The essential role in this process of complaining is given to the objects of complaints/addresses, and agents such as media, politicians, institutions such as NGOs, social movements, whistleblowers, activists and leaders.
\end{abstract}

Keywords Dissatisfaction · Political participation · Complaining

Dissatisfaction is considered to be one of the fundamental reactions of citizens and affects the decisions and operations of institutions (Lyons et al. 1992; Goodwin and Jasper 1999). People express their dissatisfaction with different issues - from the weather to social services or state policy (Hill 1972; Lyons and Lowery 1986; Budd and Gottdiener 2005). The main problem is how and by whom complaining, which in essence is a means of the expression of dissatisfaction (Kowalski 1996), is translated into political claims. The purpose of this article is to present a theoretical model of the process of strengthening or reducing the act of complaining through the actions of claim addressees and third parties, such as nongovernmental organizations or social movements. The basic framework for the proposed model is an assumption about the political potential of subjective assessments communicated in social interactions. This reflects the "critical citizens" phenomenon described by Pippa Norris, as being a group that "aspires to democracy as their ideal form of government, yet at the same time they remain deeply skeptical when evaluating how democracy works in their own country" (Norris 2011, 5).

Maciej Kowalewski

maciej.kowalewski@usz.edu.pl

1 Institute of Sociology, University of Szczecin, Ul. Krakowska 71-79, 71-017 Szczecin, Poland
This means that criticism and communication of grievances can lead to political activism only in particular circumstances, such as institutional, macro-level conditions (Harrebye and Ejrnæs 2015). The relationship between complaining and political participation is especially noticeable on the local level, where linking dissatisfaction with the sphere of politics is more obvious (Miewald and Comer 1986; Domaradzka and Wijkström 2016). Activism based on criticism, negativism and complaint may, however, be destructive or regressive: inclusion of dissatisfaction or complaints into an analysis of political activism requires deeper analyses, and this article is intended to be an introduction to these.

Although complaining is well-recognized by psychologists and economists, its political potential is still far from obvious (Ward and Ostrom 2006). One of the reasons for this is the variety of forms of expressing grievances, dissatisfaction, criticism or negative opinion and finally complaints (Alicke et al. 1992, 286). People complain in different social situations and contexts; therefore, we can differentiate between "grumbling", consumer complaints (Stephens \& Gwinner 1998, Bodey and Grace 2007, Thøgersen et al. 2009), official complaints to an ombudsman (Hill 1972) or the writing of letters to local newspapers by "concerned citizens" (Cable and Benson 1993; Bröer et al. 2016). Psychologists argue that complaining is not only a way of communicating discontent, but it is also supposed to excite compassion or draw attention (Van der 
Geest 2007). As Robin Kowalski noticed, "the fact that someone expresses dissatisfaction in the form of a complaint does not necessarily mean that the person is dissatisfied" (Kowalski 2002, 1025). This leads then (or is supposed to lead) to a specific reaction from addressees.

Both psychological and organizational perspectives (complaining as an act of interpersonal communication and complaining as an institutional relation) place stress on the individual, and the object of complaint, respectively (Daskal and Kampf 2015). Some studies show that expressing dissatisfaction is a ritual behavior endowed with psychological and social functions: instrumental, cathartic, self-presenting, egotistic, relational and identity-making (Kowalski 1996; Kaiser and Miller 2001). From the perspective of organizations, the consumer complaining behavior (CCB) function is an economic issue, as a proper reaction to a complaint enables the organization to operate more effectively by managing their public image or by increasing its effectiveness (Barlow and Møller 1996).

The tendency to complain and attitudes toward those who complain may be explained by both psychological and cultural factors. Social psychologists distinguish attitudes toward complaining (ATC) (Richins 1983) and propensity to complain (PTC) (Chulmin et al. 2003). The propensity to complain means an "individual's likelihood of seeking redress or expressing dissatisfaction to a service provider" (Bodey and Grace 2007, 580). An attitude toward complaining is to some extent independent of the complainer's personality: "it appears that $>>$ complainers $<<$ act accordingly because of their type of personality and regardless of their ATC and, therefore, they need no encouragement to complain. They desire to maintain control in situations and their belief in their own capabilities in achieving successful outcomes" (Bodey and Grace 2007, 591).

The relationship between culture and disposition to complain still needs to be further studied (Ekiz and Au 2011). The complaint, described by Berlant (1988) as a paradigm of women's public discourse, is a unique example of an analysis of the cultural contexts of dissatisfaction communication. The complaint expressed by women in the discourse of the patriarchate closes the way to political autonomy: communication of dissatisfaction is an expected and neutral message, since women are "always unhappy". As Barlant emphasizes, "it is not the woman who first call her self-articulation a complaint, a whine, a plea: rather, the patriarchal social context in which she makes her utterance hystericizes if for her, even before she speaks. As a euphemism for menstruation, 'the female complaint' typifies the banality of female suffering" (Berlant 1988, 243).

In different cultural contexts and/or relations, however, a person who complains, even if perceived as uncongenial, may be assessed as endowed with wisdom and behaving in a proper way, unlike those with an affirmation tendency (Wojciszke 2004). This means that negative discourse may be the expected and anticipated reaction. Regardless of the fact that people can complain about everything, including issues beyond their control (e.g., bad weather), the most interesting complaints are still those concerned with social relations. Such complaints pertain at the same time to the relationships between social positions and between the social actors when their structural interests or identities are endangered. In both cases, complaining stems from a reference to the sense of justice and a comparison of a normative vision with an (individual or group) actual situation. We can, therefore, speak about two directions of complaint: (1) "inward", which results in changing the relationships within a group (by upholding a common perspective and shared beliefs); and (2) "outward", when complaining enables change to the social structure.

The identity function relates to the creation of collective assessments of reality and the relational function is associated with initiating and maintaining social bonds. The latter would seem to be the case with intellectuals belonging to a "complaining social class" (klagende Klasse, see Lepenies 1992) interested in preserving existing inequalities. Robin Kowalski argues that the intensity of complaining (especially in commercial transactions), increasingly growing in Western societies, may be related to middle-class expectations that their needs must be satisfied. According to her studies, the lower classes may neutralize their own complaints, when their underprivileged situation is perceived as "natural', "invariable" and affects everybody (Kowalski 2002) - this seemingly recalls Marx's concept of ,class ideology”. The importance of class ideology, however, goes beyond the reflexivity of actors and also means the suspension of class consciousness. As Craig Calhoun notes, "A good political order must deal fairly with the fact that most people will not be politically active most of the time. That existing politics turn many people off only makes the issue more acute" (Calhoun 2002, 882). This means that social actors describe some of their actions as nonpolitical and as 'a matter of self-interest'. For example, if a neighbor complains of difficulties with public transport, although her or his story is about personal difficulties, it serves as representative for the whole community. In that sense, enhancing individual dissatisfaction allows the perception of group interests.

\section{From Expressing Dissatisfaction to Political Activity - And Back}

Castells (2015) argues that some contemporary protest movements such as Occupy lodge more complaints than political claims in their manifestos and operations. Popular dissatisfaction with participatory democracy and its procedures has become a real challenge for Western democracies (Epstein 2017), as politicians still believe that distrust can simply be managed by voting and "democracies empower partisans to pursue their interests and values through arguments and votes, 
while denying them non-democratic powers of violence or economic blackmail" (Warren 2017, 38). I would agree with Pippa Norris instead, that managing the political dissatisfaction of "critical citizens" is essential for understanding the crisis of democracy (Norris 2011).

Dissatisfaction intersects with other attitudes and actions, and it is not easy to differentiate between the expressed discontent and other forms of political activity. The semantic difference between a political action and a complaint ("expression of dissatisfaction") lies in the political expressiveness and the degree of legitimization (Crosby 1993). The legitimization of certain forms of political activities relates to admissible claims within a given system, thus actio popularis complaints may be more acceptable than e.g. consumer boycotts or street demonstrations (Tilly and Tarrow 2007). According to the classical division of conventional and unconventional activities (Barnes and Kaase 1979; Norris 2002), making complaints and criticisms are regarded as conventional, but this assumption is valid mainly for political systems in which such activity has been defined. Therefore, other authors have proposed the idea of the institutionalization of protest politics (Rucht 2003), pointing out the difference between recognizing discontent and its legitimacy, as the ideas and laws of political participation change in time. Similarly, the scope of civil rights and laws for claim-making are subject to change. Additionally, conventionality with its moral superiority becomes an evaluative category, as unconventional protest may be framed as a threat to social order (Benford and Snow 2000). Meanwhile, conventional activity and politics of protest often occur simultaneously. Moreover, protest becomes institutionalized with the passage of time (Meyer 2004). The same mechanism applies to discontent, which is linked with a political context and constitutes an impulse for the reaction of the system at the same time.

The European Social Survey (ESS 2014) provides interesting answers to questions about the relationship between dissatisfaction and political activity. Comparing mean values of general satisfaction with life and with some aspects of the situation in the country (such as the economy, education, health service) in those groups declaring their political participation or lack of it suggests significant differences for all countries. ${ }^{1}$ Activities such as organizational work or signing petitions are more likely to be undertaken by the satisfied (with life in general and with political life), whilst participation in protest politics is more likely to be undertaken by the dissatisfied. But, if we add intervening variables, new regularities may be found. For two variables (satisfaction with the way democracy works and satisfaction with the national government) the lowest mean values ${ }^{2}$ were noted in three countries - Slovenia (mean value for satisfaction with the way

\footnotetext{
${ }^{1}$ ESS 7th round survey covers 22 countries, sample size $=40,185$. T-test for independent samples was applied, $p<0.05$.

${ }^{2}$ A $0-10$ numeric rating scale was used where 0 meant 'extremely dissatisfied' and 10 extremely satisfied. Weighted sample (dweight), ESS round 7.
}

democracy works -2.90 and 2.69 for the satisfaction with the national government), France (4.31 and 2.88) and Poland (4.40 and 3.08). But, differences for respondents from those three countries declaring certain forms of political participation within the previous 12 months reveal that the high level of dissatisfaction is not connected with such activities as work in organizations or participation in legal demonstrations. The hypothesis that dissatisfaction promotes political inactivity cannot be supported, as political culture (with its entire repertoire of civil actions) is more important than the declared level of satisfaction.

What activates the political potential of citizens' dissatisfaction is not their subjective satisfaction then, but the political context, which provides a framework for the assessment of authority. Silas Harrebye and Ejrnæs (2015) studied the relationship between dissatisfaction and extra-parliamentary political activity in different European countries. Their research shows that in the Scandinavian countries this relationship is stronger than in other countries, which the authors explain with the mechanism of evaluation of democratic institutions and the impact of welfare-state. Satisfaction with the democratic system and the principles of its participation procedures is one of the most fundamental problems of democracy (Frey \& Stutzer 2001, Listhaug 2006). Some researchers argue that in democratic regimes such forms of conventional political activity as complaints and contacts with politicians are used to monitor the work of the authorities, whereas in authoritarian and postauthoritarian systems they are to ensure political stability, monitor and control the authorities and the citizens (Fitzpatrick 2015; Henry 2012). The cultural acceptance of complaining can be considered a feature of the political system - in the sense that the institutions of the system can specialize in neutralizing complaints. Reporting dysfunctions of local authorities to state representatives is characteristic for post-soviet systems - as it recalls some of the traditions of the authoritarian regime (Lussier 2010). Henry (2012) claims that formal complaints in authoritarian states strengthen authority instead of challenging it (by highlighting areas of inefficiency in the administrative apparatus; revealing corrupt practices or arbitrary conduct of lower level officials; creating the appearance of regime responsiveness and accountability to the public; addressing public dissatisfaction in a way that pre-empts collective action) (Henry 2012, 244). As Lussier states, "authoritarian regimes regularly rely on feedback from citizens to ensure that public satisfaction is high enough to guarantee popular compliance" (Lussier 2010, 313). In a democratic system, on the other hand, complaints contribute to the liberalization and improvement of the democratic system by "defending civil rights guaranteed in the constitution and other founding documents; ensuring equal application of the law; publicizing rectifying mistreatment of citizens by officials; and reinforcing the rule of law over arbitrary rule" (Henry 2012, 245). What is essential is that a publicized complaint is determined by the political context, but also 
it can transform the authority-citizen relationships, even in authoritarian systems. Publicized complaint becomes political if it allows the modification of at least some of the political procedures or issues.

The relationship between complaining and dissatisfaction is complex: one can declare dissatisfaction with the national government in a survey, and at the same time not complain about authorities in everyday conversations. Conformism in this respect is quite understandable - some people may be afraid to criticize the government openly.

Complaining is a way of communication that does not necessarily have to be associated with real dissatisfaction (and is merely a ritual or instrumental action), which means, that complaining may be interpreted by the complainers as their civil duty. If we compare complaining in relation to civil rights, then, in the first place, we would refer to the liberal tradition with its idea of the individual right of claim making. Beyond a single complaint, however, we can see the common activity for the collective benefit, which recalls the republican model of citizenship (Habermas 1992; Patten 1996), wherein the community is more important than the individual's right to claim. Political action is to a greater extent characterized by its relationship with ethics, a sense of justice and moral harm (Walzer 1973). Even if the issue of moral harm is not directly stated in claims, the very request to act together for the common good constitutes a reference to the sphere of ethical values and the idea of the moral legitimation of power (Beetham 2013).

The idea of "good authorities" with its concept of the honesty of the civil servant and their ethical responsibility are universal criteria for the assessment of the authorities. Therefore, these criteria are often used in the discourse of the tabloid press (Conboy 2005), fond of highlighting the moral depravation of officials and politicians. That critical discourse against politicians could evolve into a civil duty, the virtue of citizens' engagement. A social audit of 'concerned citizens' is usually conducted as a non-conformist activity and as such is subjected to various sanctions. In certain social circumstances, individuals either supposed to be pleased or dissatisfied with authority - Cass R. Sunstein identifies these two types of social influence that gravitate toward conformism: the actions of other people (according to the 'majority can't be wrong' rule), the desire to enjoy the good opinion of other people and the reluctance to 'make trouble' by voicing claims or starting conflicts. Sunstein underlines the fact that citizens in their political practices take into account possible losses, such as the severity of any potential punishment, loss of good reputation, strengthening of their reputation as a result of breaking the law, personal costs and profits resulting from obedience (Sunstein 2005, 61). If profits outweigh losses, a complaint may be expressed in the form of direct action. However, it takes more than rational calculation to make citizens engage in protest movements. The factors that transform indignation into organized social movements are far more complex.
Lussier (2011) indicates that complaining - similarly to civil actions, consuming political information or presenting political intentions - belongs to the group of activities which precede political participation but are different from it. In what sense can the introduction to political participation be manifested in talking to others about their assessment of their authorities? The politicalness of "talking about politics" or "complaining about politics" is hard to grasp if ordinary notions are applied, as neither talking about politics nor collective action in the absence of a political context can fulfill the criteria of political activity. According to Charles Tilly "conversation is contentious to the extent that it embodies mutual and contradictory claims, claims that, if realized, would significantly alter the longer-term behavior of at least one participant" (Tilly 2002, 114). In that sense, complaining is a political activity if it refers to or transforms the situation of a party to a political conflict. Complaining should be considered not only at the preceding stage of claim articulation, but also at subsequent stages of contentious politics. For example, in the case of a street demonstration, the complainants may refer either to the issue of representation, strategy or tactics used during the demonstration, the police's reactions, media coverage, etc.

In many cases, however, complaining supersedes political action and remains only a ritual interaction sublimating political indignation, not leading to any other forms of civil activity. Fatalism is, for example, such an attitude that eliminates any possibility of the alternative political realm (Laclau and Mouffe 2013). Fatalistic discourse (illustrated by the belief that "something is not possible") ousts political quality from the communicated dissatisfaction. In the discourse of complaint, the selected dysfunctions are irremovable, i.e. the citizens agree that there are some permanent obstacles that no one can overcome. These usually include those taken-for-granted features of the political system (described with expressions such as "nothing works properly in this country"). Gurr (2015) indicates that some groups consider the existing procedures and participatory institutions ineffective, as far as the expression of experienced detriment is concerned. Deprivation enhanced by the conviction of having the right to participate in democratic procedures reinforces the inclination to protest. Thus, it is a challenge for researchers to reconstruct hidden presuppositions concerning non-negotiable beliefs blocking all kinds of activity.

\section{Enhancing Complaining into Political Action}

The proposed model distinguishes between inactive complaining and complaining aimed at making a change, which may be reinforced or reduced. The inactive complaint is not only autotelic and ritualistic, but also (1) refers to the local negative discourse or lack of alternative to the existing authority that hinders all activity and (2) is uttered by "constantly discontented people" who are 
either inclined to complain (malcontents) or ritually criticize local authorities. Here, dissatisfaction has an identity function connected with collective evaluations of reality and a relational function involving initiating and maintaining bonds (Wojciszke et al. 2009). Complaining about one's own city becomes an interactional ritual and an expected element of group identification. (3) Complaining by the supporters of revolutionary change, rejecting the option to correct or repair the local politics. The inactive complaint may relate to the postulates of deep change, i.e. that it precludes any repair and reformist activity on a local level. In all three cases, the inactive complaint is addressed to a broad and usually unspecified audience. The last type of complaint that is not subject to reinforcement/reduction is (4) "quiet nagging" ("grumbling"), kept at the level of personal relations.

It is important to discuss whether dissatisfaction is part of everyday life and experience or whether it is influenced by global politics. Davies (2016), referring to Henri Lefebvre, points to a critical character of Everyday, which in fact is a political manifestation. In the same manner Hobson and Seabrooke (2007), emphasizing that political activity exceeds regularity, as a non-routine practice, appealing in different spaces and scales than everyday life. However, studies on urban activism shows, that people do not complain in relation to political postulates beyond the local level, but rather about local problems related to their quality of (urban) life, identity and citizenship (Polanska and Piotrowski 2015). Transferring these issues onto a level surpassing the locality, going beyond particularisms and pointing at a potential character of claims are the tasks of actors reinforcing complaints. The addressees of complaints who seek to limit their impact have to block, reduce and depoliticize claims. Authorities at the local level neutralize protests by various means (Lipsky 1969) and establishing participatory institutions deprived of any real influence is one such strategy. In some cases, participatory budgeting or social consultation are meant to transfer the responsibility for local politics to citizens (Sintomer et al. 2008). Ritualization of civic complaint - just as in authoritarian systems - renders the act of making claims superficial.

On the other hand, complaint of an instrumental nature (projecting a change) usually has an institutionalized object (addressee). Complaining oriented toward change has three forms: (1) private (interpersonal: person-to-person), (2) individual institutional (person-to-institution), and (3) collective (institution-toinstitution). The interpersonal (private) level refers to an expression of complaint while talking to friends, family or one's closest neighbors. The content of a complaint is not as important as is the dissemination of information concerning the experienced wrongs and the degree to which discontentment is politicized. Personal issues complained about may be political as well, when related to solutions of social policy: loneliness, well-being, and health are related to quality of life and the rules according to which the urban environment is (dis)organized. The essential element is to make public the private complaint - using the media, engaging an ombudsman or whistleblowers to get support, or presenting claims at a meeting of a local community may reinforce the complaint.

Studies on consumer complaints provide interesting conclusions concerning the issue of enhancing private claims. The structure of mobilization and support for the subject of a complaint shows significant similarities between the process of framing consumer dissatisfaction and making dissatisfaction a political claim. Ward and Ostrom (2006) distinguish the stages of the process: (1) presentation of the imperfections of a company providing goods/services as a violation of consumer rights, (2) enforcement of the experienced harm, (3) negative stereotyping of the company's governing bodies, (4) pointing at repeated complaints from other clients, (5) presentation of the authors of the complaint as defenders of other consumers and opposition leaders, and (6) making other consumers see themselves as a group (Ward and Ostrom 2006, 220). These stages may also be applied to complaints made by the discontented, when they could be defined as follows: (1) presentation of the subject of dissatisfaction as arising out of local authorities' operations, (2) making the experienced harms emotionally more important, (3) negative stereotyping of the authorities (but not necessarily individual civil service workers), as detached from the problems of "ordinary citizens", (4) pointing at grievances suffered by other citizens, searching for horizontal understandings, (5) depicting claim makers as people who are defending civil rights, who are fighting with the local authority corruption and bureaucracy etc., and (6) convincing public opinion that complaints constitute collective opposition against the authorities.

Citizens express their dissatisfaction not only in face-toface interactions but also via the Internet and new technologies, where critical opinion is likely to be institutionalized (Hennig-Thurau et al. 2004; Lovink 2013). Projects created in the blogosphere or social networks are interesting not only due to the creation of social worlds interested in urban problems, but because these projects allow public articulation of dissatisfaction and defense of space belonging to everyone. For example, criticism of existing inconveniences, low quality of life, and socio-spatial inequalities may be understood as new forms of urban activism. But, the questions are yet to be answered as to what extent such practices are really able to mobilize people to protest and to what extent they are used to disguise social inequality, and which of these practices only disarm the existing contradictions giving a false sense of collective interest having been articulated. A web page or Facebook profile created by a disappointed citizen fighting injustice displayed by the local authorities becomes a public act even if it is created by a single person. The framing process is, therefore, necessary to transform dissatisfaction into political claims, defining possible solutions that could be adopted by the claims' addressees with the participation of the supporting groups. 
Reinforcement able to transform a complaint into a political postulate or social movement ideology is performed by various third parties functioning as traditional watchdogs and whistleblowers. They may be individuals (leaders, activists, civic journalists, spokespersons for the complainers), non-governmental organizations as well social movements and institutions (e.g., defending the rights of minorities). All these actors reinforcing the complaint not only publicize particular cases of dissatisfaction but also acquire knowledge, document and compare cases. However, the most important role of intermediary organizations is to recognize the addressee of complaints and reinforce the submitted postulates by broadening the group of recipients and politicization of the complaint. Reinforcement is also performed by the translation of personal views and attitudes into the language of procedures and mechanisms of making claims. Formulation of an official complaint (both individual as well as those submitted by minorities with bodies representing them) allows the codification of claims and addressees using the respective laws and formal procedures. A complaint addressed to intermediaries (such as spokespersons for institutions, the media, consumer groups, trade unions, watchdogs, scholarly institutions, etc.) has its limitations (lack of a sense of belonging, no interest shown by the media) (Bradshaw et al. 1998, 210). As a result, the dissatisfied have to organize themselves and avoid institutions that do not acquit themselves well in terms of defending the oppressed.

The outlined theoretical model presenting the process of transformation of dissatisfaction into forms of political activity underlines the validity of the participation of other social actors - both organized and not organized. People complaining about local authorities do not usually complain about the mechanisms of power, but rather about particular people and their actions. Expectations regarding the level of services, duties of authorities etc. are part of political convictions and individual views, but also of situational factors in which emotions play a vital role. If complaining is aimed at protection of individual and collective interests, then various strategies are undertaken with respect to various partners in a given interaction. Complaining should be considered not only at the stage of articulation of dissatisfaction, but also at subsequent stages of the policy of opposition. For example, in the case of a protest organized in the form of a street demonstration, the complainants may refer either to the issue of representation of interests, the definition of the situation (individual or group), the course of the demonstration, the intervention of the police, or press relations, etc.

Studies show that it is not the dissatisfaction with a product or service that is the subject of the complaint, but rather it is the dissatisfaction with the standard of service provided by a sales assistant (encounter) (Thøgersen et al. 2009, 761). Therefore, the influence of individual experience with representatives of (local) authorities should be tested.
Another problem concerning this model is the structureagency relationship. Complaining belongs to normative projections of (individual and collective) social structure, and to interaction at the micro level. It is thus unclear if there is a relationship between position in the social structure and the discourse of complaint. If complaining appears as a reaction to the difference between a normative and descriptive image of the political realm, then references to the past (and the "good old days") become significant. Conservative narratives can be found in the discourse of complaining where the purpose is to defend traditional quality of life or enforce anti-modernization postulates. Those protests that have evolved around fear - e.g. against a different culture - indicate that we need to be very careful when examining such forms of making claims, which by definition mean the exclusion of certain of social categories. The difficulty with the political discontent category is connected with postulated inclusivity. The demand to deport illegal immigrants or the denial of political rights to a given group may be organized as a social movement, but surely it is an example of anti-civic action. Thus, the dissatisfaction shared by members of xenophobic groups, even if organized, will usually not be regarded as a civic movement. The normative character of terms and categories such "civic" used to analyze political activity was described by Peter Marcuse (2012). In his opinion, groups propagating the ideas of racism, homophobia, false patriotism, anti-fiscalism but also the preservation of conservative family values, protection of life (antiabortion movement), protection of private property might not be included in the group of the movements demanding the common "right to the city" (Marcuse 2012, 33). A retrotopia (Rév 1998; Bauman 2017), nostalgia (Duyvendak 2011) and other kinds of past affirmation are essential for understanding the conservative turn in the politics of the last few years. Further study is required to find out if the intensity of complaining changes with age and the growing experience of social actors or whether idealization of the past precludes positive evaluation of a present situation.

Notwithstanding the theoretical concepts of urban politics (Mollenkopf 1996), it is possible to point to some qualities of politics such as efficiency, autonomy, transparency, level of participation. Using the criteria applicable to those qualities, it is possible to formulate evaluations concerning the functioning of local politics. Citizens usually do not interpret politics scientifically, but rather employ common sense categories, e.g. "we should replace the mayor" or "I have no influence on what's going on in the city". Local complaints are also a political phenomenon because local issues that cause grievances (deprivation of needs, identity constraints, inability to access civic rights) become political topics with a supra-local dimension, as the example of urban smog perception shows (Sun et al. 2016). Urban pollution complaints relate not only to local issues but rather to state and global politics. It is not clear, however, to what extent city dwellers complain only 
about 'local politics' and to what extent about issues connected with regional or central governmental authorities.

The last problem concerns the following questions: which elements in the discourse of complaining are treated as irremovable, that is, which of them are accepted by the citizens as 'permanent' obstacles that cannot be overcome? Are these assumptions about social or economic reality? The researchers' objective is, therefore, to reconstruct hidden presuppositions about a non-negotiable social order. Jeffrey Alexander argues that civil repair - correcting the effects of another utopia - may hinder real change, because its distant goal is experienced as utopian and radical (Alexander 2001, 588). Perhaps that is why local goals seem to be more feasible. State authorities, however, in all historical contexts, are interested in containing complaints and claims of citizens within a certain limit, and prefer local governments to be responsible in a symbolic sense - for matters which directly concern citizens (Tokarska-Bakir 2014). The principle of subsidiarity is not what is pursued here, instead, the goal is to contain the complaining at a local or private level.

Open Access This article is distributed under the terms of the Creative Commons Attribution 4.0 International License (http:// creativecommons.org/licenses/by/4.0/), which permits unrestricted use, distribution, and reproduction in any medium, provided you give appropriate credit to the original author(s) and the source, provide a link to the Creative Commons license, and indicate if changes were made.

\section{Further Reading}

Alexander, J. 2001. The long and winding road: civil repair of intimate injustice. Sociological Theory, 19(3), 371-400.

Alicke, M. D., Braun, J. C., Glor, J. E., Klotz, M. L., Magee, J., Sederhoim, H., \& Siegel, R. 1992. Complaining behavior in social interaction. Personality and Social Psychology Bulletin, 18(3), 286-295.

Barlow, J., \& Møller, C. 1996. Complaint is a gift: Using customer feedback as a strategic tool. San Francisco:Berrett-Koehler.

Barnes, S. H., \& Kaase, M. 1979. Political action. Beverly Hills:Sage.

Bauman, Z. 2017. Back to Hobbes? Tikkun, 32(1), 24-29.

Beetham, D. 2013. The legitimation of power. Basingstoke:Palgrave Macmillan.

Benford, R. D., \& Snow, D. A. 2000. Framing processes and social movements: an overview and assessment. Annual Review of Sociology, 26(1), 611-639.

Berlant, L. 1988. The Female complaint. Social Text, 19(20), 237-259.

Bodey, K., \& Grace, D. 2007. Contrasting 'complainers' with'non-complainers' on attitude toward complaining, propensity to complain, and key personality characteristics: a nomological look. Psychology and Marketing, 24(7), 579-594.

Bradshaw, Y., Kendall, I., Blackmore, M., Johnson, N., \& Jenkinson, S. 1998. Complaining our way to quality: complaints, contracts and the voluntary sector. Social Policy and Administration, 32(3), 209-225.

Bröer, C., De Graaff, B., Duyvendak, J. W., \& Wester, R. 2016. Engaging citizens: local interactions, policy discourse and courses of protest against mobile phone cell site deployment. European Journal of Cultural and Political Sociology, 3(4), 447-468.
Budd, L. \& Gottdiener, M. 2005. Key concepts in urban studies (SAGE Key Concepts). Sage Publications.

Cable, S., \& Benson, M. 1993. Acting locally: environmental injustice and the emergence of grass-roots environmental organizations. Social Problems, 40(4), 464-477.

Calhoun, C. 2002. The class consciousness of frequent travelers: toward a critique of actually existing cosmopolitanism. South Atlantic Quarterly, 101(4), 869-897.

Castells, M. 2015. Networks of outrage and hope: social movements in the internet age (2Nd Edi ed., ). New York:John Wiley \& Sons.

Chulmin, K., Kim, S., Im, S., \& Shin, C. 2003. The effect of attitude and perception on consumer complaint intentions. Journal Of Consumer Marketing, 20(4), 352-371.

Conboy, M. 2005. Tabloid Britain: constructing a community through language. New York:Routledge.

Crosby, F. J. 1993. Why complain? Journal of Social Issues, 49(1), 169-184.

Daskal, E., \& Kampf, Z. 2015. Stop griping, start complaining: how public discontent can trigger a change in broadcast entertainment content. Media, Culture \& Society, 37(8), 1226-1243.

Davies, M. 2016. Everyday life as critique: Revisiting the everyday in IPE with Henri Lefebvre and postcolonialism. International Political Sociology, 10(1), 22-38.

Domaradzka, A., \& Wijkström, F. 2016. Game of the city re-negotiated: the Polish urban re-generation movement as an emerging actor in a strategic action field. Polish Sociological Review, 195(3), 291-308.

Duyvendak, J. W. 2011. The politics of home. Houndmills, Basingstoke, Hampshire:Palgrave Macmillan.

Ekiz, E. H., \& Au, N. 2011. Comparing Chinese and American attitudes towards complaining. International Journal of Contemporary Hospitality Management, 23(3), 327-343.

Epstein, W. 2017. The masses are the ruling classes. Oxford:Oxford University Press.

ESS 2014. ESS Round 7: European Social Survey Round 7 Data. Data file edition 2.0. NSD - Norwegian Centre for Research Data, Norway - Data Archive and distributor of ESS data for ESS ERIC.

Fitzpatrick, S. 2015. Everyday Stalinism. Oxford:Oxford University Press.

Goodwin, J., \& Jasper, J. M. 1999. Caught in a winding, snarling vine: The structural bias of political process theory. Sociological forum, 14(1), 27-54.

Gurr, T. R. 2015. Why men rebel. London:Routledge.

Habermas, J. 1992. Citizenship and national identity: some reflections on the future of Europe. Praxis International, 12(1), 1-19.

Harrebye, S., \& Ejrnæs, A. 2015. European patterns of participationHow dissatisfaction motivates extra-parliamentary activities given the right institutional conditions. Comparative European Politics, 13(2), 151-174.

Hennig-Thurau, T., Gwinner, K. P., Walsh, G., \& Gremler, D. D. 2004. Electronic word-of-mouth via consumer-opinion platforms: what motivates consumers to articulate themselves on the Internet? Journal of Interactive Marketing, 18(1), 38-52.

Henry, L. A. 2012. Complaint-making as political participation in contemporary Russia. Communist and Post-Communist Studies, 45(34), 243-254.

Hill, L. B. 1972. Complaining to the ombudsman as an urban phenomenon. Urban Affairs Quarterly, 8(1), 123-127.

Hobson, J. M., \& Seabrooke, L. 2007. Everyday IPE: Revealing everyday forms of change in the world economy. In J. M. Hobson, \& L. Seabrooke (Eds.), Everyday politics of the world economy. Cambridge: Cambridge University Press.

Kaiser, C. R., \& Miller, C. T. 2001. Stop complaining! The social costs of making attributions to discrimination. Personality and Social Psychology Bulletin, 27(2), 254-263.

Kowalski, R. M. 1996. Complaints and complaining: functions, antecedents, and consequences. Psychological Bulletin, 119(2), 179-196. 
Kowalski, R. M. 2002. Whining, griping, and complaining: positivity in the negativity. Journal of Clinical Psychology, 58(9), 1023-1035.

Laclau, E., \& Mouffe, C. 2013. Hegemony and socialist strategy. London:Verso.

Lepenies, W. 1992. Aufstieg und Fall der Intellektuellen in Europa. Frankfurt/Main:Campus Verlag.

Lipsky, M. 1969. Rent strikes: poor man's weapon. Society, 6(4), 10-15. Lovink, G. 2013. Zero comments. Hoboken:Taylor and Francis.

Lussier, D. N. 2011. Contacting and complaining: political participation and the failure of democracy in Russia. Post-Soviet Affairs, 27(3), 289-325.

Lyons, W. E., \& Lowery, D. 1986. The organization of political space and citizen responses to dissatisfaction in urban communities: an integrative model. The Journal of Politics, 48(2), 321-346.

Lyons, W. E., Lowery, D., \& Dehoog, R. H. 1992. The politics of dissatisfaction: citizens, services, and urban institutions. Armonk:Sharpe.

Marcuse, P. 2012. Whose right(s) to what city? In N. Brenner, P. Marcuse, \& M. Mayer (Eds.), Cities for People, Not for Profit. London: Routledge.

Meyer, D. S. 2004. Protest and political opportunities. Annual Review of Sociology, 30(1), 125-145.

Miewald, R. D., \& Comer, J. C. 1986. Complaining as participation. Administration \& Society, 17(4), 481-499.

Mollenkopf, J. 1996. How to study urban political power. In T. LeGates, \& F. Stout (Eds.), The City Reader. London: Routledge.

Norris, P. 2002. Democratic phoenix. Cambridge:Cambridge University Press.

Norris, P. 2011. Democratic deficit: Critical citizens revisited. New York: Cambridge University Press.

Patten, A. 1996. The republican critique of liberalism. British Journal of Political Science, 26(1), 25-44.

Polanska, D. V., \& Piotrowski, G. 2015. The transformative power of cooperation between social movements: squatting and tenants' movements in Poland. City, 19(2-3), 274-296.

Rév, I. 1998. Retrotopia: critical reason turns primitive. Current Sociology, 46(2), 51-80.

Richins, M. L. 1983. Negative word-of-mouth by dissatisfied consumers: a pilot study. Journal Of Marketing, 47(1), 68-78.

Rucht, D. 2003. The changing role of political protest movements. West European Politics, 26(4), 153-176.

Sintomer, Y., Herzberg, C., \& Röcke, A. 2008. Participatory budgeting in Europe: potentials and challenges. International Journal of Urban and Regional Research, 32(1), 164-178.

Sun, C., Yuan, X., \& Xu, M. 2016. The public perceptions and willingness to pay: from the perspective of the smog crisis in China. Journal of Cleaner Production, 112, 1635-1644.
Sunstein, C. 2005. Why societies need dissent. Harvard:Harvard University Press.

Thøgersen, J., Juhl, H. J., \& Poulsen, C. S. 2009. Complaining: a function of attitude, personality, and situation. Psychology and Marketing, 26(8), 760-777.

Tilly, C. 2002. Stories, identities, and political change. Oxford:Rowman \& Littlefield.

Tilly, C., \& Tarrow, S. G. 2007. Contentious politics. Boulder:Paradigm Press.

Tokarska-Bakir, J. 2014. Complaints and their researchers. East European Politics and Societies, 28(2), 296-317.

Van Der Geest, S. 2007. Complaining and not complaining: Social strategies of older people in Kwahu, Ghana. Global Ageing, 4(3), 55-65.

Walzer, M. 1973. Political action: the problem of dirty hands. Philosophy \& Public Affairs, 2(2), 160-180.

Ward, J. C., \& Ostrom, A. L. 2006. Complaining to the masses: the role of protest framing in customer-created complaint Web sites. Journal of Consumer Research, 33(2), 220-230.

Warren, M. E. 2017. What kinds of trust does a democracy need? Trust from the perspective of democratic theory. In S. Zmerli, \& T. W. G. van der Meer (Eds.), Handbook on Political Trust. Cheltenham Glos: Edward Elgar Publishing.

Wojciszke, B. 2004. The negative social world: The Polish culture of complaining. International Journal of Sociology, 34(4), 38-59.

Wojciszke, B., Baryła, W., Szymków-Sudziarska, A., Parzuchowski, M., \& Kowalczyk, K. 2009. Saying is experiencing: affective consequences of complaining and affirmation. Polish Psychological Bulletin, 40(2), 74-84.

Publisher's Note Springer Nature remains neutral with regard to jurisdictional claims in published maps and institutional affiliations.

Maciej Kowalewski is a Professor and Director at the Institute of Sociology, University of Szczecin, Poland. His research and teaching are in the domains of urban and political sociology. In early 2019 he was a visiting associate at LSE Cities. His works has been published in Space and Polity, Space and Culture, Sustainability (among others), he has co-edited Transforming Urban Sacred Places in Poland and Germany. 